\title{
A Novel Flower-Like Ag/AgCl/BiOCOOH Ternary Heterojunction Photocatalyst: Facile Construction and Its Superior Photocatalytic Performance for the Removal of Toxic Pollutants
}

\author{
Shijie Li ${ }^{1, *}$, Bing Xue ${ }^{1,2}$, Genying $\mathrm{Wu}^{3}$, Yanping Liu ${ }^{1,2, *}$, Huiqiu Zhang ${ }^{1}{ }^{\mathbb{D}}$, Deyun Ma ${ }^{4}$ \\ and Juncheng $\mathrm{Zuo}^{2}$ \\ 1 Key Laboratory of key technical factors in Zhejiang seafood health hazards, Institute of Innovation \\ \& Application, Zhejiang Ocean University, Zhoushan 316022, China; xb1725621827@163.com (B.X.); \\ zhanghuiqiu2006@163.com (H.Z.) \\ 2 College of Marine Science and Technology, Zhejiang Ocean University, Zhoushan 316022, China; \\ zjuncheng@zjou.edu.cn \\ 3 Longquan Branch of Lishui Municipal Ecological Environment Bureau, Longquan 323700, China; \\ hannah29@163.com \\ 4 School of Food and Pharmaceutical Engineering, Zhaoqing University, Zhaoqing 526061, China; \\ mady@zqu.edu.cn \\ * Correspondence: lishijie@zjou.edu.cn (S.L.); liuyp@zjou.edu.cn (Y.L.)
}

Received: 27 September 2019; Accepted: 31 October 2019; Published: 4 November 2019

\begin{abstract}
Novel 3D flower-like $\mathrm{Ag} / \mathrm{AgCl} / \mathrm{BiOCOOH}$ ternary heterojunction photocatalysts were fabricated by the solvothermal and in-situ precipitation methods, followed by light reduction treatment. The $\mathrm{Ag} / \mathrm{AgCl}$ nanoparticles were homogeneously distributed on 3D $\mathrm{BiOCOOH}$ microspheres. These obtained catalysts were characterized by XRD, SEM, TEM, diffuse reflectance spectra (DRS), and photoluminescence (PL). As expected, they exhibited extraordinary photocatalytic capabilities for the elimination of rhodamine $B(\mathrm{RhB})$ and ciprofloxacin (CIP) under simulated sunlight, the results revealed that the $\mathrm{Ag} / \mathrm{AgCl} / \mathrm{BiOCH}-3$ with 20 wt. $\%$ of $\mathrm{Ag} / \mathrm{AgCl}$ possessed the maximum activity, and the rate constant for the $\mathrm{RhB}$ degradation reached up to $0.1353 \mathrm{~min}^{-1}$, which was about 16.5 or 12.2 times that of bare $\mathrm{BiOCOOH}$ or $\mathrm{Ag} / \mathrm{AgCl}$. The PL characterization further verified that $\mathrm{Ag} / \mathrm{AgCl} / \mathrm{BiOCOOH}$ heterojunctions were endowed with the effective separation of photogenerated carriers. The excellent photocatalytic ability of $\mathrm{Ag} / \mathrm{AgCl} / \mathrm{BiOCOOH}$ could be credited to the synergistic interactions between $\mathrm{Ag} / \mathrm{AgCl}$ and $\mathrm{BiOCOOH}$, which not only substantially widened the light absorption, but also evidently hindered the charge recombination. The trapping experiments revealed that the dominant reactive species in $\mathrm{RhB}$ removal were $\mathrm{h}^{+}, \bullet \mathrm{OH}$, and $\bullet \mathrm{O}_{2}{ }^{-}$species. In addition, $\mathrm{Ag} / \mathrm{AgCl} / \mathrm{BiOCOOH}$ was quite stable and easily recyclable after multiple cycles. The above results imply that the 3D flower-like $\mathrm{Ag} / \mathrm{AgCl} / \mathrm{BiOCOOH}$ ternary heterojunction photocatalyst holds promising prospects in treating industrial wastewater.
\end{abstract}

Keywords: $\mathrm{Ag} / \mathrm{AgCl} / \mathrm{BiOCOOH}$; ternary heterojunction; toxic pollutants; photocatalysis

\section{Introduction}

The massive development of global industry has brought about the aggravation of environmental pollution. Especially, contamination of refractory pollutants (e.g., industrial dyes and pharmaceutical antibiotics) in the aquatic environment poses an overwhelming threat to human health. To mitigate this problem, scientists have been devoted to exploring effective and eco-friendly techniques $[1,2]$. Among them, semiconductor-mediated photocatalysis has been deemed as a sustainable and efficient 
technology for environmental protection [3-8]. In the field of photocatalysis, $\mathrm{BiOCOOH}(\mathrm{Eg}=\sim 3.7 \mathrm{eV})$ has recently emerged as a promising candidate for wastewater treatment by virtue of its unique layer architecture, high chemical stability, and non-toxicity $[9,10]$. However, the photocatalytic performance of $\mathrm{BiOCOOH}$ is still unsatisfactory due to the insufficient sunlight absorption and rapid carrier recombination. Therefore, great efforts have been made to reinforce the photocatalytic capability of $\mathrm{BiOCOOH}[9,11-17]$. Of note, the fabrication of semiconductor heterojunctions is an effective route to conquer these drawbacks $[11-15,17,18]$. In this regard, searching for an appropriate candidate to be integrated with $\mathrm{BiOCOOH}$ for the efficient removal of pollutants has been very anticipated but challenging.

$\mathrm{Up}$ to now, $\mathrm{Ag} / \mathrm{AgCl}$ has been widely utilized to modify different semiconductors for triggering extraordinary photocatalytic capability because of its ability to efficaciously improve the visible light $(\mathrm{VL})$ response using the surface plasmon resonance (SPR) effect of metallic Ag and boost the separation of electrons and holes [19-25]. For instance, $\mathrm{Ag} / \mathrm{AgCl} / \mathrm{titanium}$ phosphate [25], $\mathrm{Ag} / \mathrm{AgCl} / \mathrm{TiO}_{2}$ [22], and $\mathrm{Ag} / \mathrm{AgCl} / \mathrm{SrTiO} 3$ [21] have been constructed and have displayed superior VL photocatalytic activity. Based on band theory, the band structures of $\mathrm{Ag} / \mathrm{AgCl}$ and $\mathrm{BiOCOOH}$ are suitable for the generation of a novel plasmonic "type II" heterojunction, which could efficiently promote the separation of photo-excited charge carriers during the photocatalytic process. Enlightened by the above consideration, the novel hierarchical heterostructure of $\mathrm{BiOCOOH}$ decorated with $\mathrm{Ag} / \mathrm{AgCl}$ nanoparticles can be expected to be a highly efficient photocatalyst for pollutant elimination under simulated sunlight.

Herein, in this work, a novel 3D flowerlike $\mathrm{Ag} / \mathrm{AgCl} / \mathrm{BiOCOOH}$ ternary heterojunction photocatalyst has been successfully synthesized through a facile solvothermal-precipitation-photoreduction route. $\mathrm{Ag} / \mathrm{AgCl} \mathrm{NPs}$ were evenly deposited in $\mathrm{BiOCOOH}$ micro-flowers, enabling fast separation of carriers and better absorption of light via the multi-reflection of light. The underlying properties and photocatalytic capability toward the removal of rhodamine $\mathrm{B}(\mathrm{RhB})$ and ciprofloxacin (CIP) in aqueous solution were systematically investigated. The possible photocatalysis mechanism regarding the transfer and segregation of charge carriers was proposed. This study offers deep insight into the design of highly efficient ternary heterojunction photocatalysts for wastewater treatment.

\section{Materials and Methods}

\subsection{Chemicals}

All chemicals of analytical grade were purchased from Chinese Chemical Reagent factory (Shanghai, China) and utilized as was received without further purification.

\subsection{Photocatalysts Preparation}

Synthesis of BiOCOOH microspheres: First, $1 \mathrm{mmol}$ of $\mathrm{Bi}\left(\mathrm{NO}_{3}\right)_{3} \cdot 5 \mathrm{H}_{2} \mathrm{O}$ was dissolved in the solution of $25 \mathrm{~mL}$ of glycerol, $10 \mathrm{~mL}$ of $\mathrm{H}_{2} \mathrm{O}$, and $10 \mathrm{~mL}$ of DMF with continuous stirring for $2 \mathrm{~h}$. After that, the resulting solution was put into a $50 \mathrm{~mL}$ autoclave and then reacted at $160{ }^{\circ} \mathrm{C}$ for $24 \mathrm{~h}$. When the reaction completed, $\mathrm{BiOCOOH}$ microspheres were rinsed repeatedly and then dried at $60^{\circ} \mathrm{C}$ overnight.

Synthesis of $\mathrm{AgCl} / \mathrm{BiOCOOH}$ heterojunctions: First, $0.32 \mathrm{~g}$ of $\mathrm{BiOCOOH}$ was evenly dispersed in $70 \mathrm{~mL}$ of solution containing $0.143 \mathrm{~g}$ of $\mathrm{AgNO}_{3}$ and $0.15 \mathrm{~g}$ of polyvinylpyrrolidone (PVP) under ultrasonic conditions to form solution $\mathrm{A}$, and the resultant solution A was magnetically stirred for $1 \mathrm{~h}$. Subsequently, $0.36 \mathrm{~g}$ of $\mathrm{NaCl}$ was dissolved in $20 \mathrm{~mL}$ of deionized water to form solution $\mathrm{B}$. Then, solution B was injected into solution A by employing a syringe pump at a speed of $3 \mathrm{~mL} / \mathrm{h}$ under vigorous agitation (1000 r/min), and the system was further stirred for $1 \mathrm{~h}$. Afterwards, the $30 \mathrm{wt} . \%$ $\mathrm{AgCl} / \mathrm{BiOCOOH}$ sample with a mass ratio of $\mathrm{AgCl}$ to $\mathrm{BiOCOOH}$ of $30 \%$ was totally rinsed to remove $\mathrm{Na}^{+}$and $\mathrm{Cl}^{-}$ions and then dried at $70{ }^{\circ} \mathrm{C}$. 
Synthesis of $\mathrm{Ag} / \mathrm{AgCl} / \mathrm{BiOCOOH}$ ternary heterojunctions: $0.4 \mathrm{~g} \mathrm{AgCl} / \mathrm{BiOCOOH}$ was suspended in the solution of $30 \mathrm{~mL} \mathrm{H}_{2} \mathrm{O}$ and $30 \mathrm{~mL}$ ethanol, followed by stirring for $30 \mathrm{~min}$. After that, the mixture was irradiated by a $300 \mathrm{~W}$ Xe lamp for $2 \mathrm{~h}$ with continuous stirring. The as-prepared $30 \mathrm{wt} . \%$ $\mathrm{Ag} / \mathrm{AgCl} / \mathrm{BiOCOOH}$ was washed with deionized water thoroughly and dried at $70{ }^{\circ} \mathrm{C}$ in a vacuum oven and denoted as $\mathrm{Ag} / \mathrm{AgCl} / \mathrm{BiOCH}-4$. Similarly, 5 wt.\% $\mathrm{Ag} / \mathrm{AgCl} / \mathrm{BiOCOOH}(\mathrm{Ag} / \mathrm{AgCl} / \mathrm{BiOCH}-1)$, 10 wt. $\%$ Ag/AgCl/BiOCOOH (Ag/AgCl/BiOCH-2), 20 wt.\% Ag/AgCl/BiOCOOH (Ag/AgCl/BiOCH-3), $\mathrm{AgCl}$, and $\mathrm{Ag} / \mathrm{AgCl}$ were also synthesized.

\subsection{Characterization}

The crystal constituents of the as-prepared samples were determined by using a $X$-ray diffraction (XRD, MiniFlex 600, Rigaku, Japan) diffractometer (Cu-Ka radiation at $40 \mathrm{kV}$ and $15 \mathrm{~mA}, \lambda=0.15418 \mathrm{~nm}$, $2 \theta$ in the range from 20 to $80^{\circ}$ ). Microstructures of the as-fabricated catalysts were observed using a scanning electron microscope (SEM, Hitachi S-4800, Tokyo, Japan) and transmission electron microscope (TEM, Tecnai G2F20, Philips, Amsterdam, The Netherlands). UV-vis diffuse reflectance spectra (DRS) of the as-fabricated samples were collected using a UV-vis spectrophotometer (Shimadzu UV-2600, Tokyo, Japan). Photoluminescence (PL) analyses were implemented on a spectrophotometer (Hitachi F-7000, Tokyo, Japan).

\subsection{Photocatalytic Tests}

Photocatalytic tests were conducted with RhB or CIP as the target pollutant over different samples under ambient conditions [26,27]. A 300 W Xe lamp (NeT HSX-300, Beijing, China) without a light filter to remove the UV light was employed as the simulated sunlight source. In each test, $30 \mathrm{mg}$ of catalysts was first added into $80 \mathrm{~mL}$ of RhB $(10 \mathrm{mg} / \mathrm{L})$ or CIP $(10 \mathrm{mg} / \mathrm{L})$ aqua-solutions in a $250 \mathrm{~mL}$ beaker. Afterward, the resulting suspension was continuously agitated for $60 \mathrm{~min}$ in the dark. After that, the lamp was switched on to trigger the photocatalytic reaction. During the photocatalytic reaction, $3 \mathrm{~mL}$ of suspension was collected at a predetermined time interval and centrifuged $(5000 \mathrm{rpm}$, $5 \mathrm{~min}$ ) to separate aliquot from solid particles for further assessment of the photodegradation rate. The absorbance was monitored using an UV-vis spectrophotometer (Shimadzu UV-2600), and the normalized concentration variations of RhB and CIP were obtained based on their corresponding maximum absorption at 554 and $276 \mathrm{~nm}$, respectively. The degradation rate $(\eta)$ of $\mathrm{RhB}$ or CIP was estimated by the following equation: $\eta=\left(C_{0}-C_{t}\right) / C_{0} \times 100 \%$, where $C_{0}$ and $C_{t}$ are the absorbance of the pollutant solution before irradiation and the absorbance of the pollutant solution at irradiation time $t$, respectively.

The reusability and stability of $\mathrm{Ag} / \mathrm{AgCl} / \mathrm{BiOCH}-3$ were measured via repeating the uniform experiment for six runs, and each run involved $30 \mathrm{~min}$ of dark adsorption and $30 \mathrm{~min}$ of reaction. After each run, the photocatalyst was first separated from the RhB aqueous solution via centrifugation (5000 rpm, $3 \mathrm{~min}$ ), and then rinsed thoroughly with deionized water and ethanol, dried at $70{ }^{\circ} \mathrm{C}$ for $10 \mathrm{~h}$, and subsequently subjected to the next run.

Mineralization degrees of RhB solution with the as-fabricated samples as the catalysts during the reaction were determined via measuring the total organic carbon (TOC) on a TOC analyzer (Shimadzu TOC-LCSH/CPH, Tokyo, Japan).

\section{Results and Discussion}

\subsection{Structure and Morphology}

The crystalline phases of $\mathrm{BiOCOOH}, \mathrm{AgCl}$, and $\mathrm{Ag} / \mathrm{AgCl} / \mathrm{BiOCOOH}$ heterojunctions with various contents of $\mathrm{Ag} / \mathrm{AgCl}$ were characterized by $\mathrm{XRD}$ (Figure 1). For pure $\mathrm{BiOCOOH}$, all the diffraction peaks coincided well with those of the tetragonal BiOCOOH (JCPDS 35-0939) [11,15]. Pristine AgCl was crystalized in a cubic phase (JCPDS 31-1238) with distinct diffraction peaks at $27.8^{\circ}, 32.4^{\circ}, 46.3^{\circ}$, $54.6^{\circ}, 57.3^{\circ}$, and $74.5^{\circ}$, corresponding to the (111), (200), (220), (311), (222), and (331) crystal facets, 
respectively $[23,28]$. As to the $\mathrm{Ag} / \mathrm{AgCl} / \mathrm{BiOCOOH}$ heterojunctions, besides the peaks from $\mathrm{BiOCOOH}$, several diffraction peaks belonging to $\mathrm{Ag}$ and $\mathrm{AgCl}$ were also detected, proving the successful fabrication of $\mathrm{Ag} / \mathrm{AgCl} / \mathrm{BiOCOOH}$ heterojunctions. Notably, as the content of the $\mathrm{Ag} / \mathrm{AgCl}$ increased, the intensities of $\mathrm{Ag} / \mathrm{AgCl}$ peaks gradually improved. Additionally, no other signals of impurities were detected, signifying the high purity of these heterojunctions. Meanwhile, the introduction of $\mathrm{Ag} / \mathrm{AgCl} \mathrm{NPs}$ did not lead to the phase change of $\mathrm{BiOCOOH}$, implying that the $\mathrm{Ag} / \mathrm{AgCl}$ NPs were probably coated on the $\mathrm{BiOCOOH}$ nanosheets instead of covalently incorporating into the crystal lattices of $\mathrm{BiOCOOH}$.

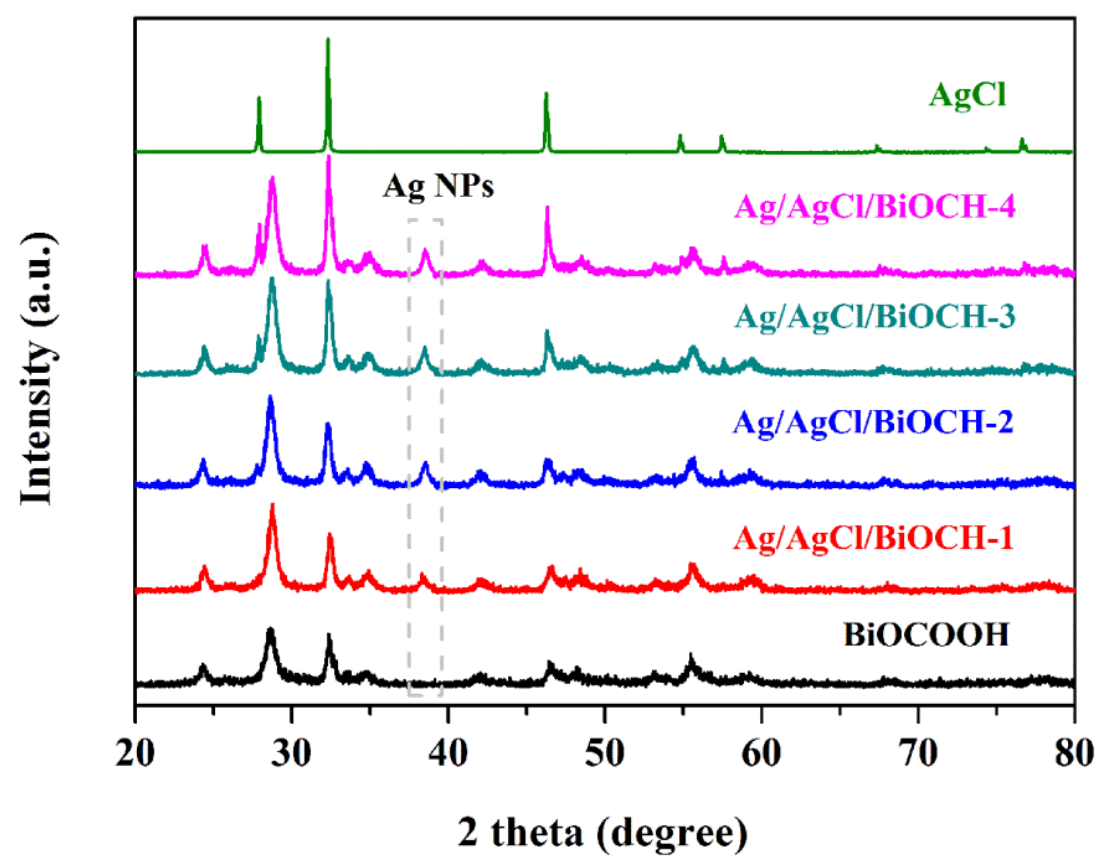

Figure 1. $\mathrm{XRD}$ patterns of $\mathrm{BiOCOOH}, \mathrm{AgCl}$, and $\mathrm{Ag} / \mathrm{AgCl} / \mathrm{BiOCOOH}$ heterojunctions $(\mathrm{Ag} / \mathrm{AgCl} / \mathrm{BiOCH}-1$, $\mathrm{Ag} / \mathrm{AgCl} / \mathrm{BiOCH}-2, \mathrm{Ag} / \mathrm{AgCl} / \mathrm{BiOCH}-3$, and $\mathrm{Ag} / \mathrm{AgCl} / \mathrm{BiOCH}-4)$.

The morphological and microstructural features of $\mathrm{BiOCOOH}$ and the $\mathrm{Ag} / \mathrm{AgCl} / \mathrm{BiOCOOH}$ heterojunction $(\mathrm{Ag} / \mathrm{AgCl} / \mathrm{BiOCH}-3)$ were investigated based on SEM and TEM measurements (Figures 2 and 3). Pristine BiOCOOH possessed 3D hierarchical flower-like structures (diameter: $\sim 2$ to $3 \mu \mathrm{m}$ ) assembled by numerous 2D nanosheets (size: 400 to $900 \mathrm{~nm}$ ) (Figure 2a,b). When combined with the $\mathrm{Ag} / \mathrm{AgCl} \mathrm{NPs}$, the as-prepared $\mathrm{Ag} / \mathrm{AgCl} / \mathrm{BiOCOOH}$ heterojunctions still consisted of hierarchical microspheres without apparent morphological changes. Representatively, $\mathrm{Ag} / \mathrm{AgCl} / \mathrm{BiOCH}-3$ displayed a 3D hierarchical microsphere shape (Figure 2c). Close inspection of the SEM image (Figure 2d) reveals that numerous $\mathrm{Ag} / \mathrm{AgCl} \mathrm{NPs}$ were compactly coated on the $2 \mathrm{D}$ nanosheets of $\mathrm{BiOCOOH}$, proving the formation of the $\mathrm{Ag} / \mathrm{AgCl} / \mathrm{BiOCOOH}$ heterojunction. 

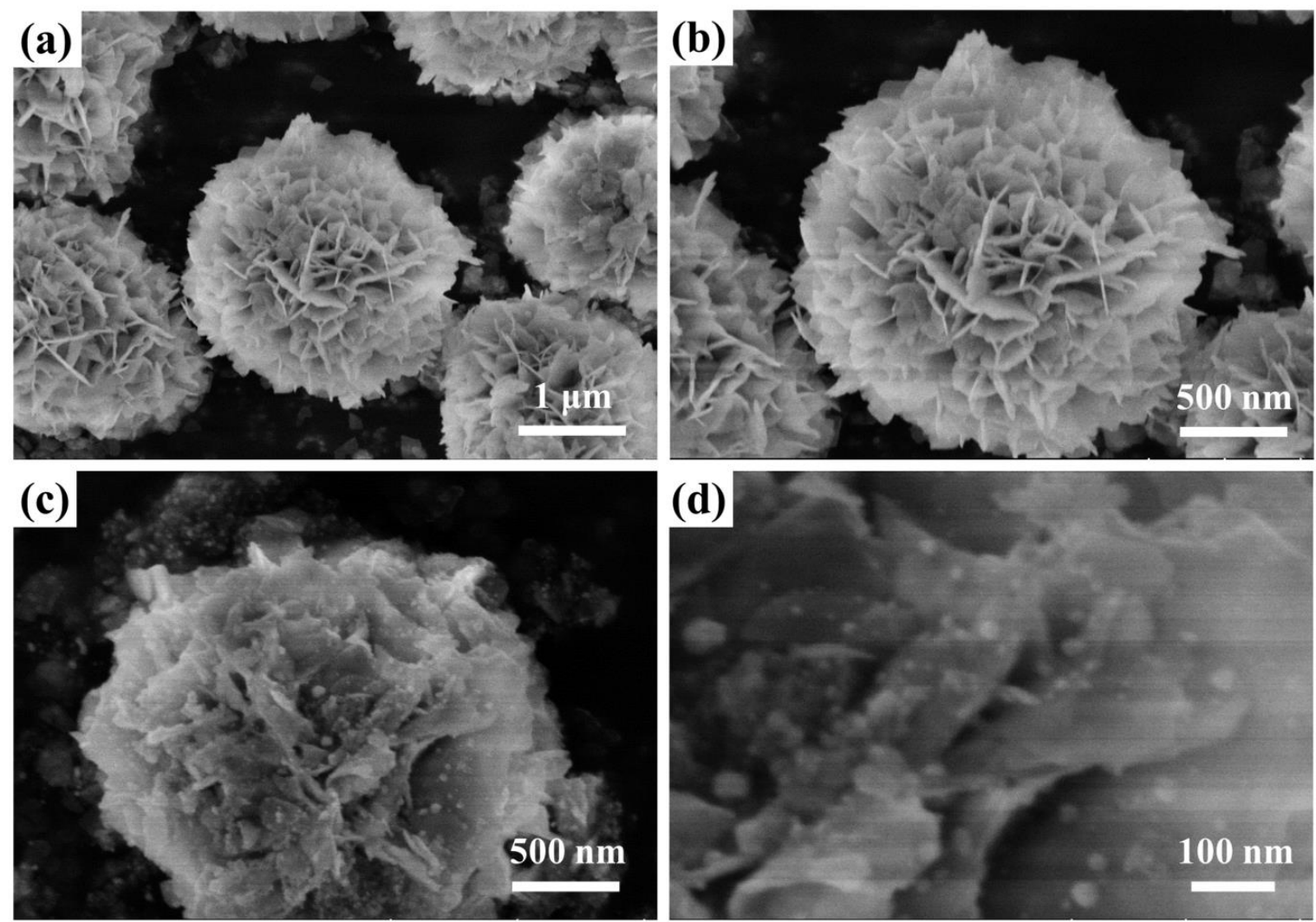

Figure 2. SEM images of (a,b) $\mathrm{BiOCOOH}$ and (c,d) $\mathrm{Ag} / \mathrm{AgCl} / \mathrm{BiOCH}-3$.
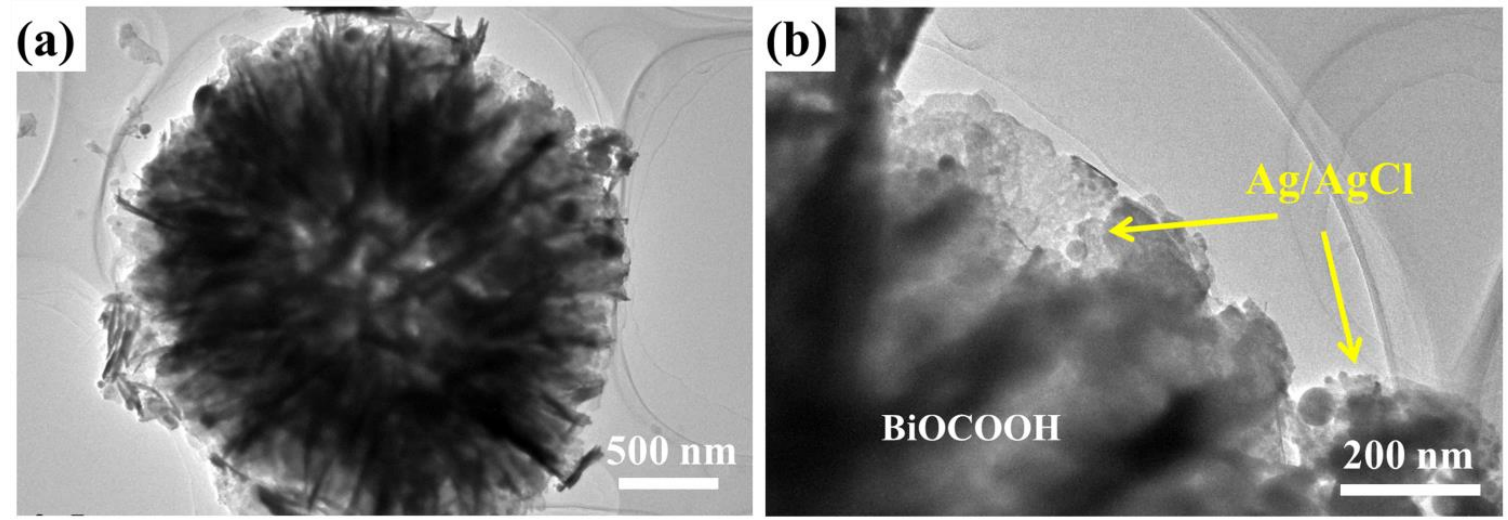

Figure 3. (a,b) TEM images of $\mathrm{Ag} / \mathrm{AgCl} / \mathrm{BiOCH}-3$.

TEM images were further collected to provide insights into the microstructure of $\mathrm{Ag} / \mathrm{AgCl} / \mathrm{BiOCH}-3$. As expected, the TEM images (Figure 3a,b) reveal similar results to the SEM images (Figure 2c,d), confirming that the $\mathrm{Ag} / \mathrm{AgCl} \mathrm{NPs}$ (size: $\sim 20$ to $70 \mathrm{~nm}$ ) were closely embedded in a flower-like BiOCOOH via an in-situ growth process. The in-situ deposition of $\mathrm{Ag} / \mathrm{AgCl} \mathrm{NPs}$ on $\mathrm{BiOCOOH}$ spheres ensured the compact contact of interfaces between them, benefiting the separation of photo-induced charge carriers and further enhancing the photocatalytic capability of these ternary heterojunctions. Based on these characterizations, it can be inferred that the $\mathrm{Ag} / \mathrm{AgCl} / \mathrm{BiOCOOH}$ ternary heterojunction with tight interfacial contact has been successfully fabricated by a simple in-situ precipitation route.

\subsection{Optical Properties}

The optical responses of $\mathrm{BiOCOOH}, \mathrm{AgCl}$, and $\mathrm{Ag} / \mathrm{AgCl} / \mathrm{BiOCOOH}$ heterojunctions were measured by UV-Vis spectrophotometry (Figure 4). Bare BiOCOOH presents an intense absorption 
in the UV region up to $\sim 370 \mathrm{~nm}$, in line with that in the reported literature [10]. When integrated with $\mathrm{Ag} / \mathrm{AgCl} \mathrm{NPs}$, all $\mathrm{Ag} / \mathrm{AgCl} / \mathrm{BiOCOOH}$ heterojunctions display a remarkable improvement in $\mathrm{VL}$ absorption, mainly due to the SPR effect of Ag NPs. This fact indicates that $\mathrm{Ag} / \mathrm{AgCl} / \mathrm{BiOCOOH}$ heterojunctions are capable of harvesting more sunlight to efficiently decompose toxic contaminants as compared to pure $\mathrm{BiOCOOH}$. In addition, the absorption edge $\left(\lambda_{\mathrm{g}}\right)$ of $\mathrm{AgCl}$ is $\sim 387 \mathrm{~nm}$. According to the following formula: $\mathrm{Eg}=1240 / \lambda_{\mathrm{g}}$, the band gap energy $(\mathrm{Eg})$ values of $\mathrm{BiOCOOH}$ and $\mathrm{AgCl}$ are determined as 3.40 [10] and $3.21 \mathrm{eV}$ [23], respectively.

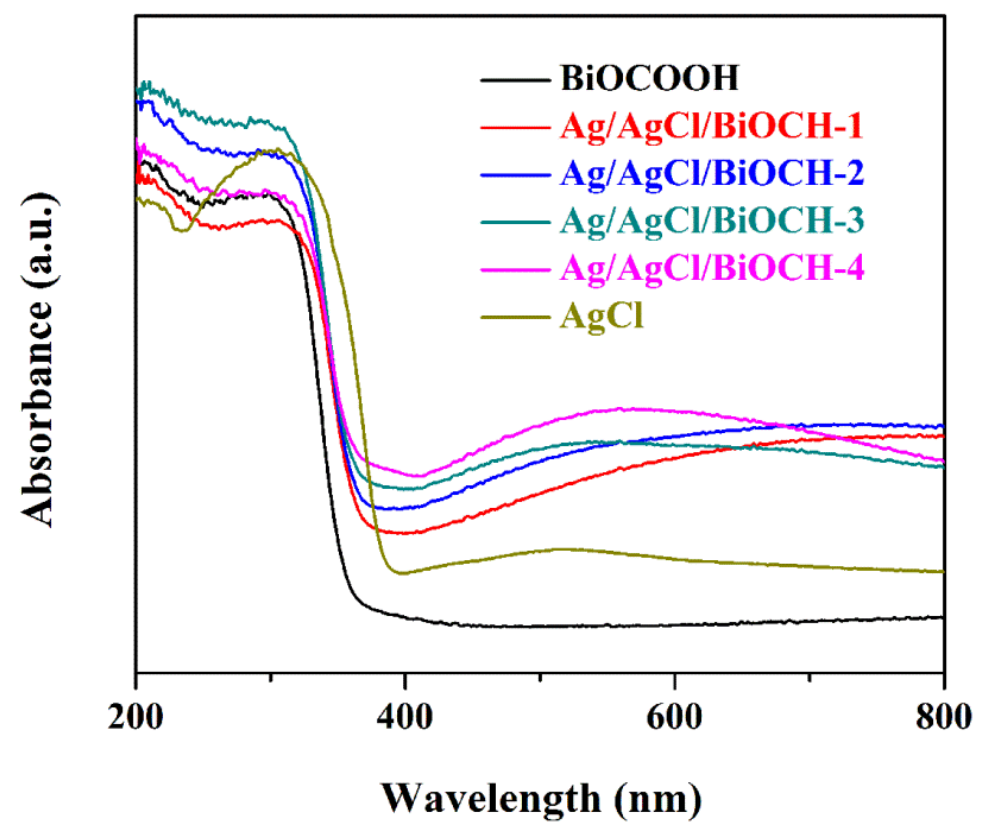

Figure 4. $\mathrm{UV}$-vis DRS of $\mathrm{BiOCOOH}, \mathrm{AgCl}$, and $\mathrm{Ag} / \mathrm{AgCl} / \mathrm{BiOCOOH}$ heterojunctions $(\mathrm{Ag} / \mathrm{AgCl} / \mathrm{BiOCH}-1$, $\mathrm{Ag} / \mathrm{AgCl} / \mathrm{BiOCH}-2, \mathrm{Ag} / \mathrm{AgCl} / \mathrm{BiOCH}-3$, and $\mathrm{Ag} / \mathrm{AgCl} / \mathrm{BiOCH}-4)$.

\subsection{Photocatalytic Activity}

The photocatalytic capabilities of $\mathrm{BiOCOOH}, \mathrm{Ag} / \mathrm{AgCl}$, and $\mathrm{Ag} / \mathrm{AgCl} / \mathrm{BiOCOOH}$ heterojunctions were measured for the elimination of RhB. Figure 5 a displays the photodegradation rates of RhB over various samples. The blank experiment verified the structural stability of the RhB compound in the absence of any photocatalysts, and the photolysis of RhB was negligible after $60 \mathrm{~min}$ of simulated solar irradiation. The photocatalytic activities of the samples followed the order: $\mathrm{Ag} / \mathrm{AgCl} / \mathrm{BiOCH}-3>\mathrm{Ag} / \mathrm{AgCl} / \mathrm{BiOCH}-4>\mathrm{Ag} / \mathrm{AgCl} / \mathrm{BiOCH}-2>\mathrm{Ag} / \mathrm{AgCl} / \mathrm{BiOCH}-1>\mathrm{Ag} / \mathrm{AgCl}>$ $\mathrm{BiOCOOH}>$ a mixture of $\mathrm{Ag} / \mathrm{AgCl}$ and $\mathrm{BiOCOOH}$. These $\mathrm{Ag} / \mathrm{AgCl} / \mathrm{BiOCOOH}$ heterojunctions exhibited prominently improved photocatalytic activity than $\mathrm{Ag} / \mathrm{AgCl}$ and $\mathrm{BiOCOOH}$ owing to the formation of the ternary heterostructure. Moreover, the photocatalytic results also signified the significance of the optimum amount of $\mathrm{Ag} / \mathrm{AgCl}$ toward the photocatalytic activities of the as-prepared heterojunctions. The photocatalytic activity first rose with the increase in $\mathrm{Ag} / \mathrm{AgCl}$ content. When the $\mathrm{Ag} / \mathrm{AgCl}$ content reached $20 \mathrm{wt}$ \%, the as-prepared $\mathrm{Ag} / \mathrm{AgCl} / \mathrm{BiOCH}-3$ was demonstrated to be the best candidate among all the as-prepared catalysts, and it only took about 40 min to completely decompose $\mathrm{RhB}$, which could be credited to the improved photo-absorption capacity (Figure 4) and the markedly suppressed recombination of charge carriers. However, when the content of $\mathrm{Ag} / \mathrm{AgCl}$ was 30 wt.\%, the photocatalytic activity slumped, which could be due to the fact that the aggregation of $\mathrm{Ag} / \mathrm{AgCl}$ undermined the efficient separation of carriers. Furthermore, a blend sample denoted as a mixture was also applied to degrade the RhB solution, and approximately $67.7 \%$ of $\mathrm{RhB}$ was eliminated, verifying the establishment of the heterojunction in $\mathrm{Ag} / \mathrm{AgCl} / \mathrm{BiOCH}-3$ and the eminent role of the heterojunction in determining the photocatalytic performance. 

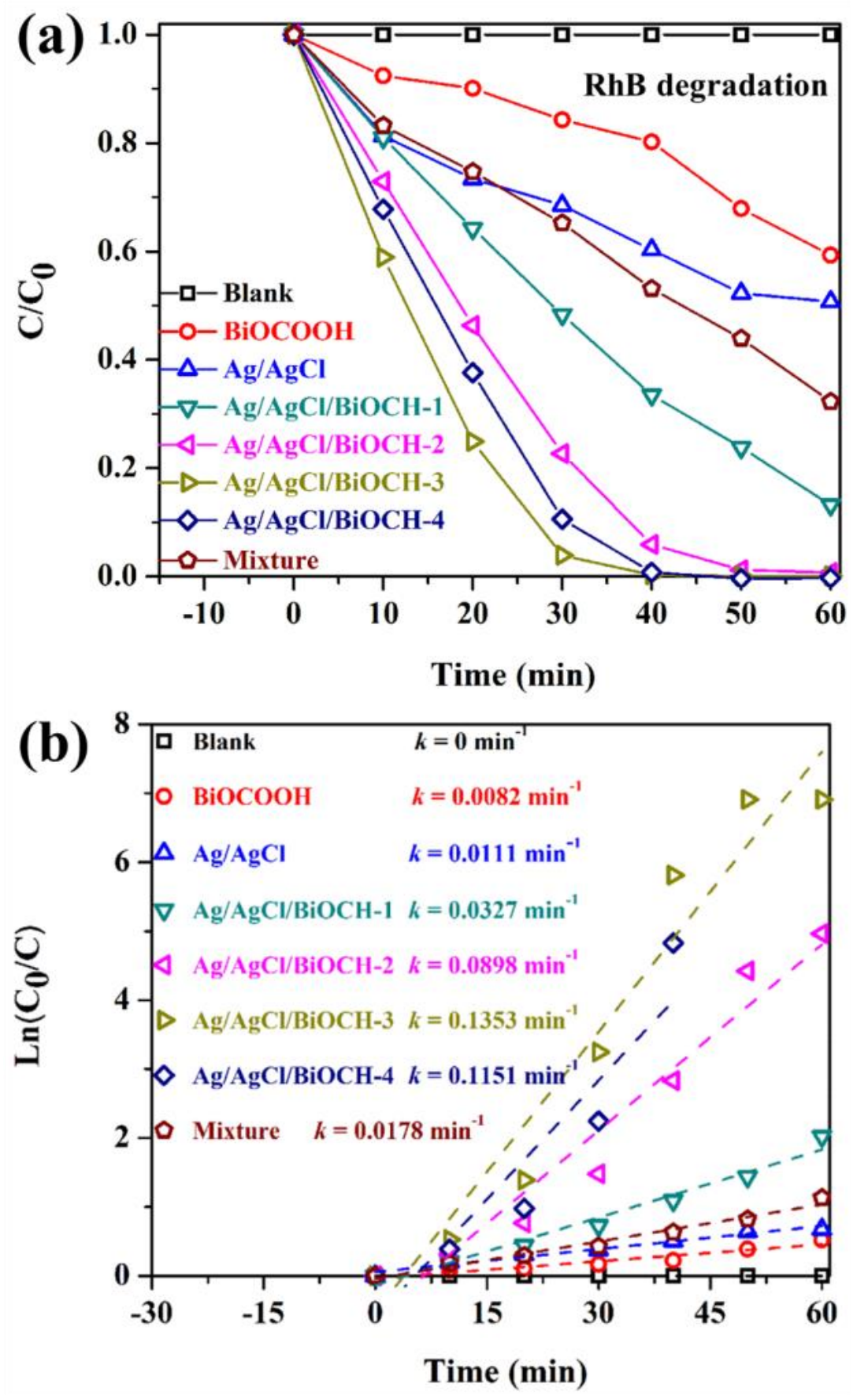

Figure 5. (a,b) Photocatalytic removal of rhodamine B (RhB) $(10 \mathrm{mg} / \mathrm{L}, 80 \mathrm{~mL})$ over as-obtained photocatalysts $(30 \mathrm{mg}$ ) under simulated sunlight.

Additionally, according to the formula of $-\ln \left(C / C_{0}\right)=k t$, the apparent degradation rate constants $(k)$ over various catalysts were calculated in Figure $5 \mathrm{~b}$. Remarkably, $\mathrm{Ag} / \mathrm{AgCl} / \mathrm{BiOCH}-3$ bore the highest $k$ value of $0.1353 \mathrm{~min}^{-1}$ that was around 15.5 or 11.2 times greater than that of pure $\mathrm{BiOCOOH}$ $\left(0.0082 \mathrm{~min}^{-1}\right)$ or $\mathrm{Ag} / \mathrm{AgCl}\left(0.0111 \mathrm{~min}^{-1}\right)$, respectively.

$\mathrm{CIP}$, a colorless antibiotic, was selected as a probe to further appraise the photocatalytic capability of $\mathrm{Ag} / \mathrm{AgCl} / \mathrm{BiOCH}-3$ (Figure 6). As expected, the CIP degradation efficiency over $\mathrm{Ag} / \mathrm{AgCl} / \mathrm{BiOCH}-3$ $(86.9 \%)$ was much greater than that over $\mathrm{BiOCOOH}(29.8 \%)$, or $\mathrm{Ag} / \mathrm{AgCl}(38.8 \%)$, further verifying the high photocatalytic capability of $\mathrm{Ag} / \mathrm{AgCl} / \mathrm{BiOCH}-3$. 


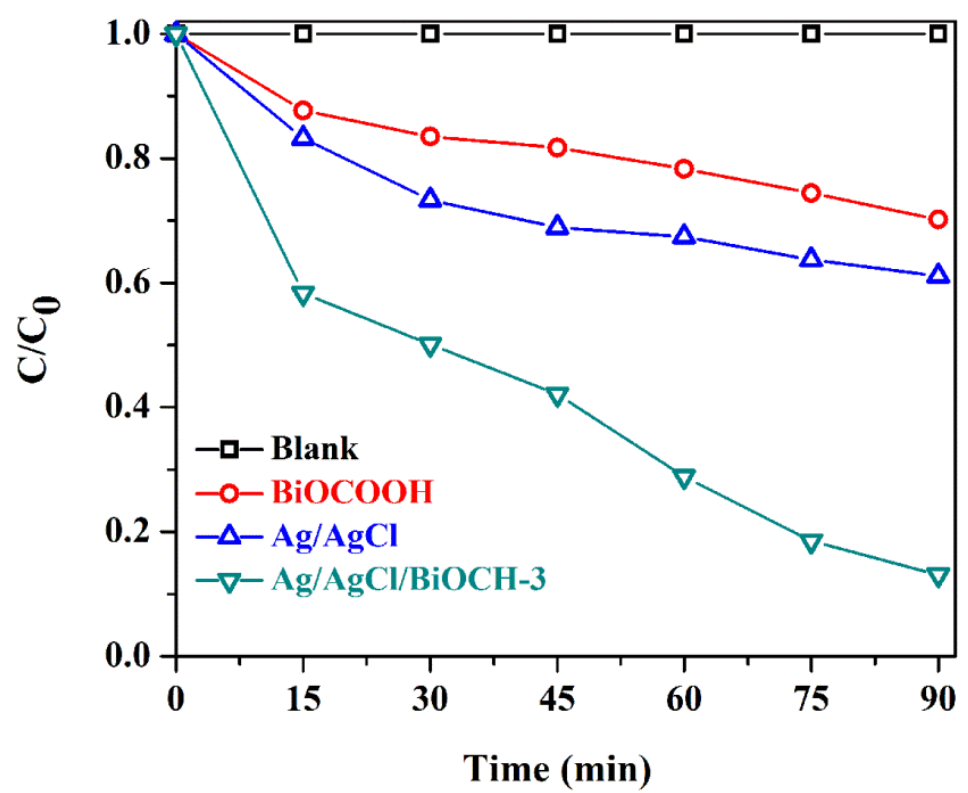

Figure 6. Photocatalytic removal of ciprofloxacin (CIP) $(10 \mathrm{mg} / \mathrm{L}, 80 \mathrm{~mL})$ over different photocatalysts (30 mg) under simulated sunlight.

For elucidation of the mineralization capacity of the as-prepared samples, TOC measurements were implemented during the degradation of $\mathrm{RhB}(10 \mathrm{mg} / \mathrm{L}, 80 \mathrm{~mL})$ using $\mathrm{Ag} / \mathrm{AgCl} / \mathrm{BiOCH}-3, \mathrm{BiOCOOH}$, or $\mathrm{Ag} / \mathrm{AgCl}$ as the photocatalyst. As shown in Figure 7a, $\mathrm{Ag} / \mathrm{AgCl} / \mathrm{BiOCH}-3$ presented an excellent mineralization capability, and about $54.9 \%$ of RhB was mineralized after 60 min, which was much higher than that by $\mathrm{BiOCOOH}(16.7 \%)$ or $\mathrm{Ag} / \mathrm{AgCl}(21.6 \%)$.

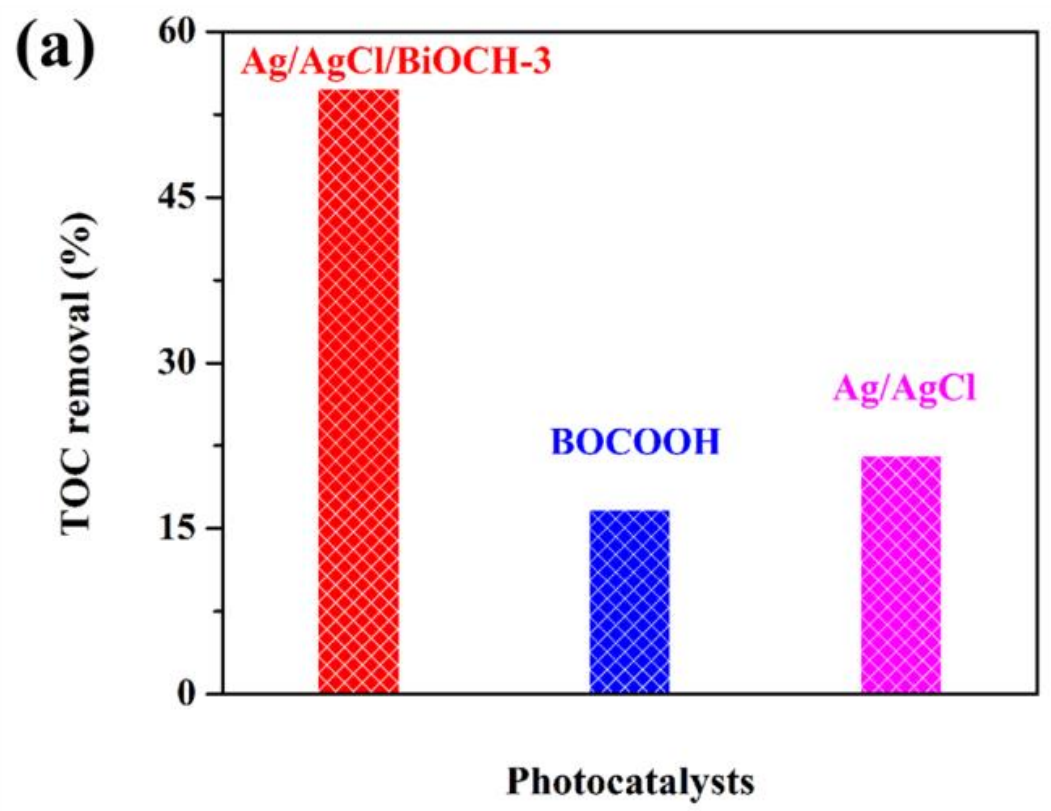

Figure 7. Cont. 


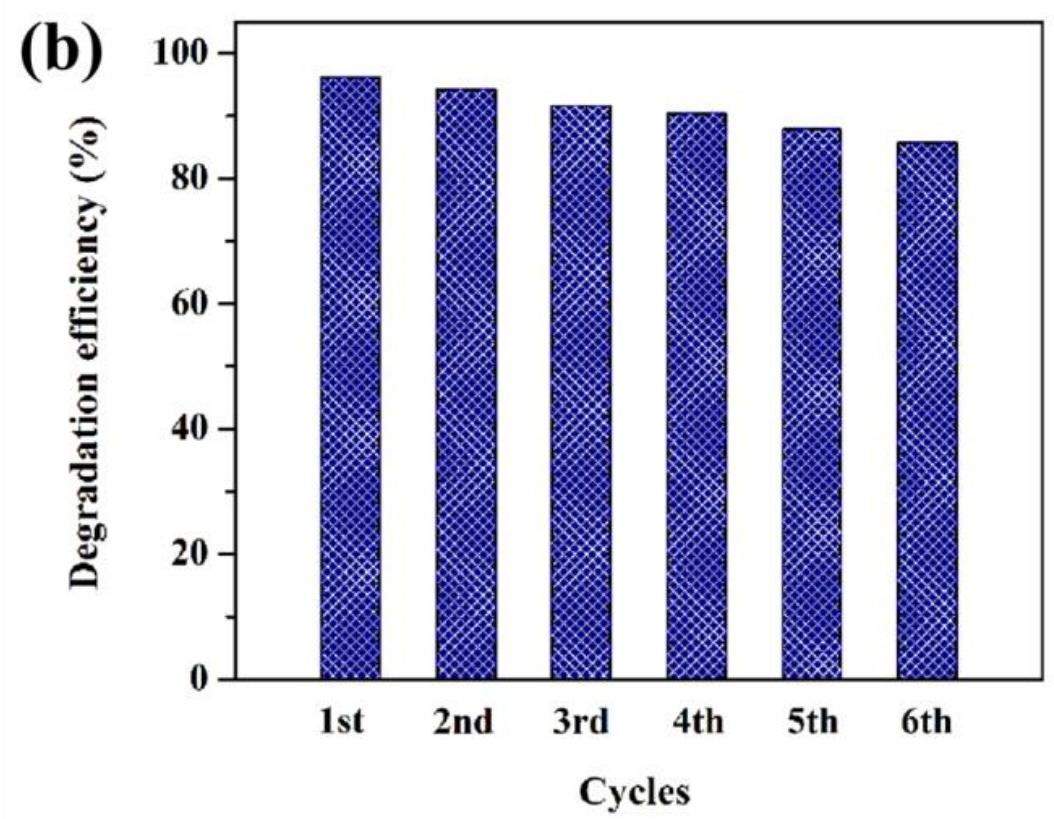

Figure 7. (a) TOC removal of $\mathrm{RhB}(10 \mathrm{mg} / \mathrm{L}, 80 \mathrm{~mL})$ over $\mathrm{Ag} / \mathrm{AgCl} / \mathrm{BiOCH}-3(30 \mathrm{mg}), \mathrm{BiOCOOH}$ $(30 \mathrm{mg})$, or $\mathrm{Ag} / \mathrm{AgCl}(30 \mathrm{mg})$ after $60 \mathrm{~min}$ of illumination; (b) recycling tests of $\mathrm{Ag} / \mathrm{AgCl} / \mathrm{BiOCH}-3$ (30 mg) for RhB (10 mg/L, $80 \mathrm{~mL})$ removal.

Recyclability of a photocatalyst is another important parameter for practical utilization in industry $[29,30]$. Hence, recycling experiments for $\mathrm{RhB}$ degradation by $\mathrm{Ag} / \mathrm{AgCl} / \mathrm{BiOCH}-3$ were executed. In each run, $30 \mathrm{~min}$ of dark adsorption and $30 \mathrm{~min}$ of visible-light irradiation were involved. As displayed in Figure $7 \mathrm{~b}, \mathrm{Ag} / \mathrm{AgCl} / \mathrm{BiOCH}-3$ showed satisfactory photocatalytic behavior without apparent loss of activity even after six successive runs. Moreover, the XRD technique was employed to characterize the recycled $\mathrm{Ag} / \mathrm{AgCl} / \mathrm{BiOCH}-3$ after six runs. As observed in Figure $\mathrm{S} 1$, no additional peaks were detected compared to those in the XRD pattern of the fresh $\mathrm{Ag} / \mathrm{AgCl} / \mathrm{BiOCH}-3$, proving the stable crystalline structure. In other words, the $\mathrm{Ag} / \mathrm{AgCl} / \mathrm{BiOCH}-3$ ternary heterojunction is a kind of stable photocatalyst that can be utilized for at least six runs with steady photocatalytic activity.

\subsection{Reaction Mechanism}

To elucidate the photocatalytic mechanism of pollutant degradation over the $\mathrm{Ag} / \mathrm{AgCl} / \mathrm{BiOCH}-3$ ternary heterojunction, radical quenching tests were first conducted by using $1 \mathrm{mM}$ of ammonium oxalate (AO), isopropyl alcohol (IPA), and benzoquinone (BQ) to scavenge $\mathrm{h}^{+}, \bullet \mathrm{OH}$, and $\bullet \mathrm{O}_{2}{ }^{-}$species, respectively (Figure 8) [31]. Clearly, the introduction of $\mathrm{AO}$, IPA, and $\mathrm{BQ}$ made the RhB degradation efficiencies drastically decline from $100 \%$ to $53.8 \%, 33.2 \%$, and $58.6 \%$, respectively, verifying that $\mathrm{h}^{+}$, $\bullet \mathrm{OH}$, and $\bullet \mathrm{O}_{2}{ }^{-}$reactive species were produced and collectively involved in the pollutant degradation by $\mathrm{Ag} / \mathrm{AgCl} / \mathrm{BiOCH}-3$.

To further illustrate the principle behind the enhanced photocatalytic property of the $\mathrm{Ag} / \mathrm{AgCl} / \mathrm{BiOCH}-3$ heterojunction, photoluminescence (PL) spectra were measured to analyze the migration and separation of photo-induced carriers [32,33]. In general, the stronger the PL intensity, the faster the recombination speed of the charge carriers, and, hence, the weaker the photocatalytic capability $[14,15,29,30,32-34]$. As displayed in Figure 9, BiOCOOH showed a tough PL peak situated at $\sim 370 \mathrm{~nm}$, indicating that the reunion speed of the electrons and holes was fast. By contrast, $\mathrm{Ag} / \mathrm{AgCl} / \mathrm{BiOCH}-3$ presented a much weaker emission peak than $\mathrm{BiOCOOH}$, which signified that the reunion of photo-excited carriers was substantially hindered by the introduction of $\mathrm{Ag} / \mathrm{AgCl} \mathrm{NPs}$, implying the enhanced photocatalytic capability. 


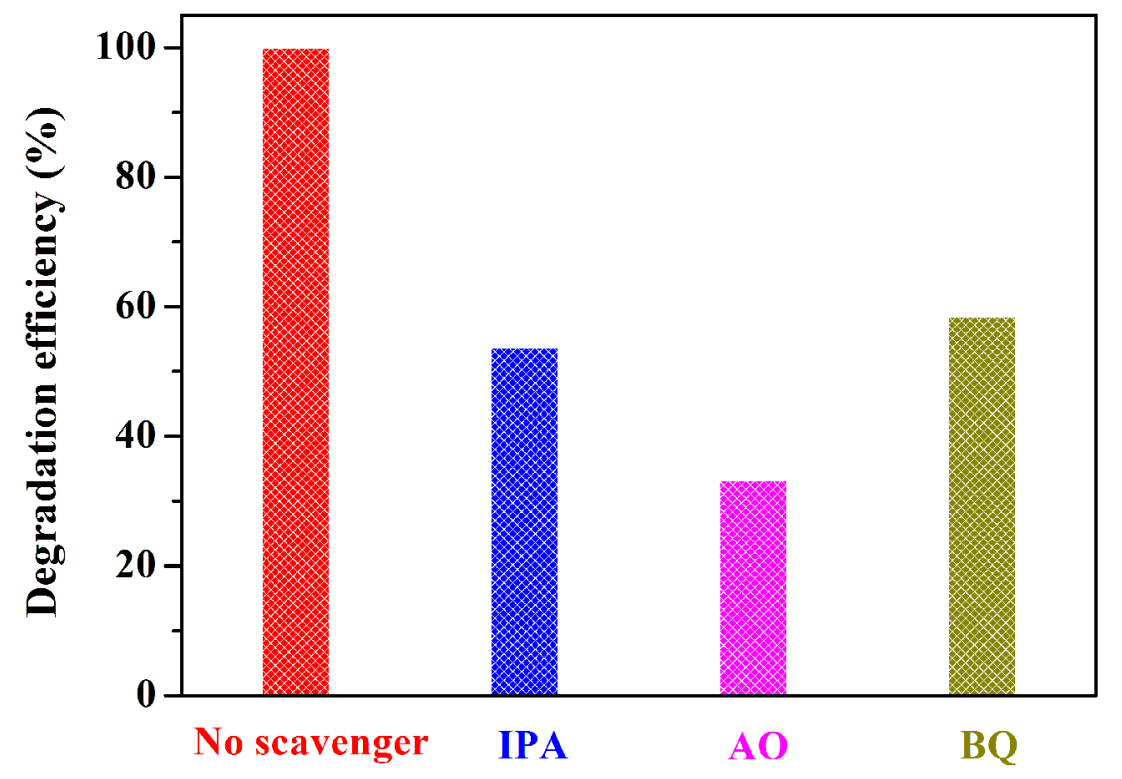

Figure 8. Influences of different quenchers on the photocatalytic capability of $\mathrm{Ag} / \mathrm{AgCl} / \mathrm{BiOCH}-3$.

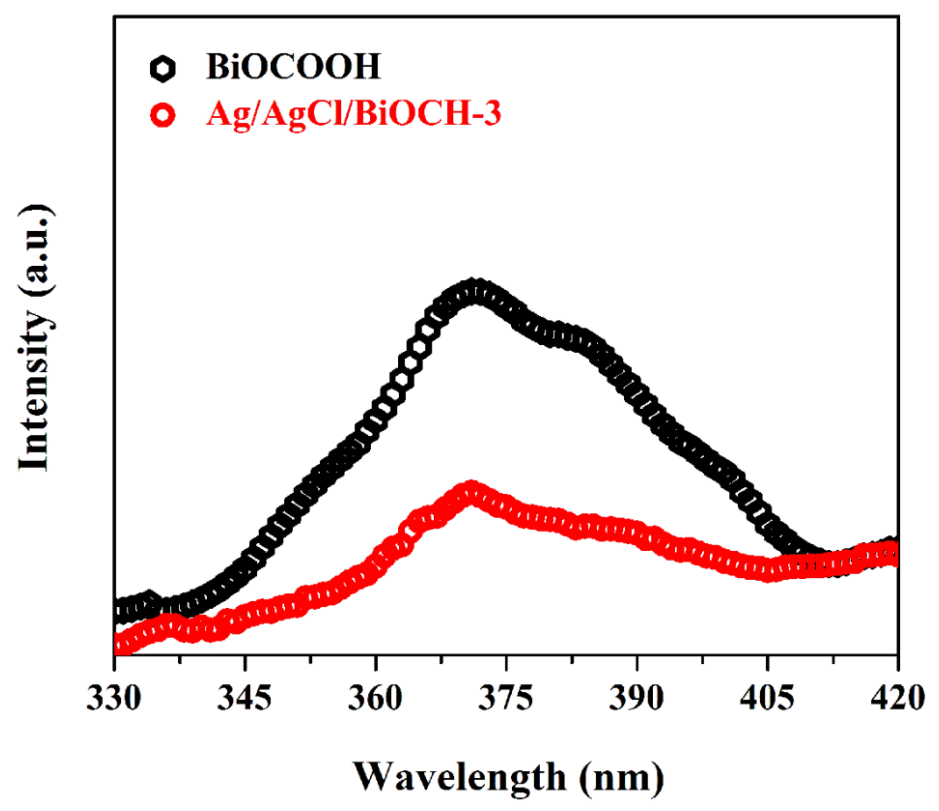

Figure 9. PL spectra of $\mathrm{BiOCOOH}$ and $\mathrm{Ag} / \mathrm{AgCl} / \mathrm{BiOCH}-3$.

It is well known that the band positions of the constituents of the heterojunction play a crucial role in determining the transfer pathway of photogenerated electrons and holes [35]. As reported, the $\mathrm{CB}$ potential $\left(E_{\mathrm{CB}}\right)$ and $\mathrm{VB}$ potential $\left(E_{\mathrm{VB}}\right)$ of $\mathrm{BiOCOOH}$ are -0.67 and $+2.73 \mathrm{~V}$ (versus Normal Hydrogen Electrode (NHE)), respectively [36], while those of $\mathrm{AgCl}$ are -0.06 and $+3.15 \mathrm{~V}$ (versus $\mathrm{NHE}$ ), respectively [37].

In view of the above characterization, photocatalytic performances, and radical trapping experiment, a plausible photocatalytic mechanism for the elimination of toxic contaminants over the $\mathrm{Ag} / \mathrm{AgCl} / \mathrm{BiOCOOH}$ ternary heterojunction photocatalyst is put forward in Figure 10. The excellent photocatalytic performance of $\mathrm{Ag} / \mathrm{AgCl} / \mathrm{BiOCOOH}$ mainly gives credit to the fascinating ternary heterostructure, which remarkably promotes the separation of charge carriers and ameliorates the sunlight absorption capability $[38,39]$. With simulated sunlight illumination, both $\mathrm{BiOCOOH}$ and $\mathrm{AgCl}$ can harvest the photons with energies greater than 3.4 and $3.21 \mathrm{eV}$ to generate electrons and 
holes on their CB and VB, respectively. The photo-excited electrons on the $\mathrm{CB}$ of BiOCOOH can be easily injected into the $\mathrm{CB}$ of $\mathrm{AgCl}$. Afterward, the metallic Ag NPs function as electron sinks to accept electrons from the $\mathrm{CB}$ of $\mathrm{AgCl}$ and, consequently, these accumulated electrons on the surface of $\mathrm{Ag}$ NPs can be scavenged by $\mathrm{O}_{2}$ to produce $\bullet \mathrm{O}_{2}{ }^{-}$reactive species (Figure 8). Notably, the electron transfer process could effectively inhibit the photo-corrosion of $\mathrm{AgCl}$, further contributing to the high stability of the ternary hetero-structure. Meanwhile, the holes on the $\mathrm{VB}$ of $\mathrm{AgCl}$ tend to thermodynamically flow into the $\mathrm{VB}$ of $\mathrm{BiOCOOH}$. Subsequently, parts of the holes left on the $\mathrm{VB}$ of $\mathrm{BiOCOOH}$ can react with $\mathrm{H}_{2} \mathrm{O}$ to form $\bullet \mathrm{OH}$ radicals, while the rest of the holes with a powerful oxidation capacity can directly decompose the pollutants (Figure 8). To sum up, by virtue of the well-matched band alignment of the ternary hetero-structure, the produced $\mathrm{h}^{+}, \bullet \mathrm{OH}$, and $\bullet \mathrm{O}_{2}{ }^{-}$reactive species primarily contributed to the efficient degradation and mineralization of toxic contaminants (RhB/CIP).

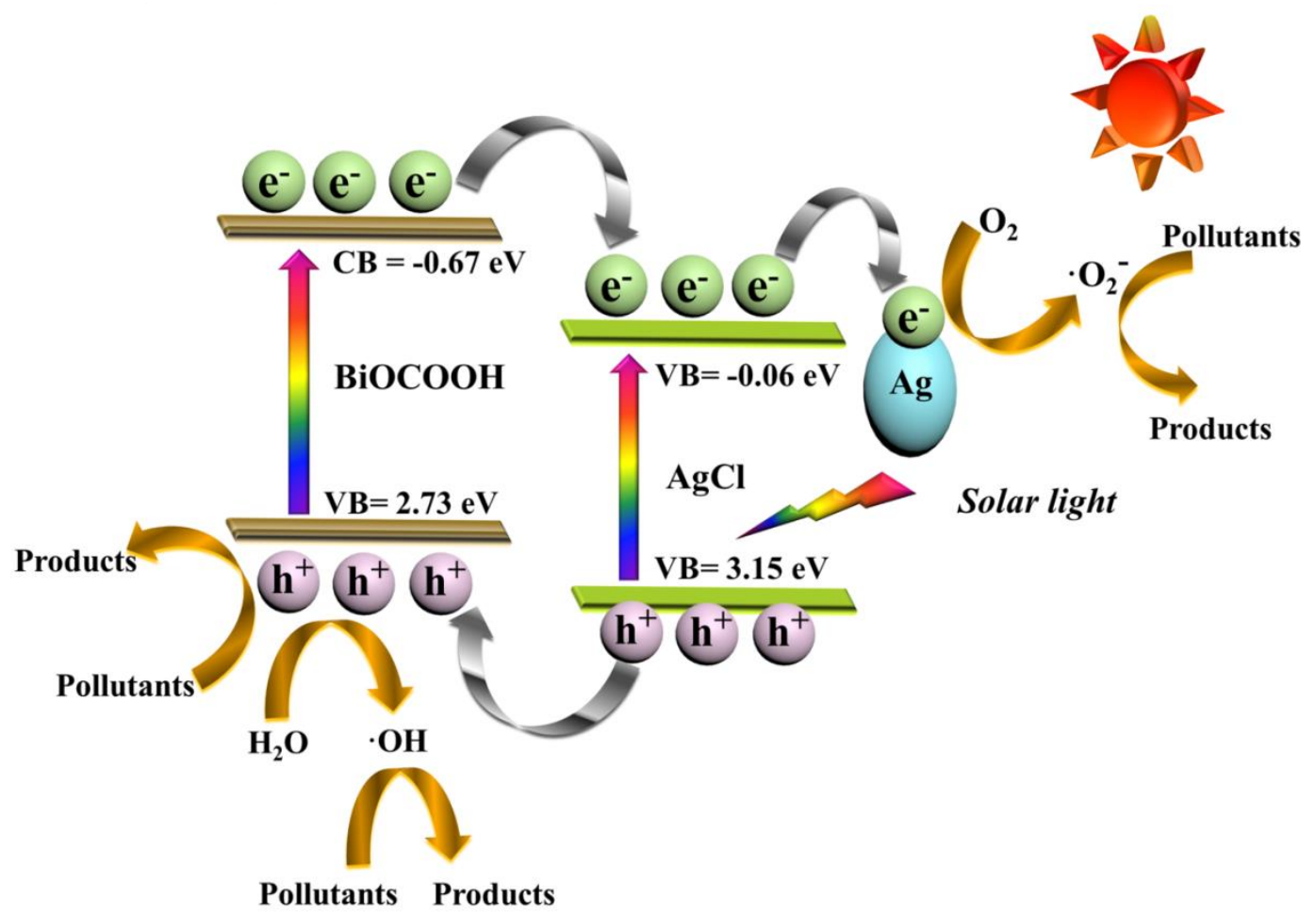

Figure 10. Photocatalytic mechanism of the ternary $\mathrm{Ag} / \mathrm{AgCl} / \mathrm{BiOCOOH}$ heterojunction photocatalyst under simulated sunlight.

\section{Conclusions}

A novel 3D flower-like $\mathrm{Ag} / \mathrm{AgCl} / \mathrm{BiOCOOH}$ ternary heterojunction photocatalyst was successfully constructed via loading $\mathrm{AgCl} \mathrm{NPs}$ on $\mathrm{BiOCOOH}$ microspheres, followed by photoreduction. The photocatalytic capabilities of these samples were assessed through the photocatalytic destruction of RhB and CIP under simulated sunlight. The $\mathrm{Ag} / \mathrm{AgCl} / \mathrm{BiOCH}-3$ ternary heterojunction photocatalyst displayed the best photocatalytic capability, and the RhB and CIP degradation efficiencies could achieve $100 \%$ and $86.9 \%$, respectively. The extraordinary photocatalytic capability was primarily credited to the merits of the enhanced sunlight harvesting capability and evidently suppressed recombination of photo-induced carriers, originating from the synergistic effect of the novel ternary heterojunction system. The trapping experiments demonstrated that $\mathrm{h}^{+}, \bullet \mathrm{OH}$, and $\bullet \mathrm{O}_{2}{ }^{-}$reactive species collaboratively contributed to the degradation of pollutants. Moreover, $\mathrm{Ag} / \mathrm{AgCl} / \mathrm{BiOCH}-3$ possessed a good stability and strong mineralization capability. Therefore, this work not only offers an excellent ternary heterojunction photocatalyst, but might also provide a facile method for constructing 3D microsphere ternary heterojunction catalysts for photocatalytic applications. 
Supplementary Materials: Supplementary data associated with this article can be found at http://www.mdpi. com/2079-4991/9/11/1562/s1, in the online version, Figure S1: XRD patterns of the original and recovered $\mathrm{Ag} / \mathrm{AgCl} / \mathrm{BOCH}-3$.

Author Contributions: S.L.: idea, and design of the paper; performed the tests; analyzed the data; wrote this paper. B.X., Y.L., G.W., H.Z., D.M. and J.Z. assisted the characterizations.

Funding: This work has been financially supported by the Fundamental Research Funds for Zhejiang Provincial Universities and Research Institutes (2019JZ00009), the National Natural Science Foundation of China (51708504), the Public Projects of Zhejiang Province (LGN18E080003), the Science and Technology Project of Zhoushan (2017C41006), the Zhaoqing City of Science and Technology Innovation Project (201804030101), and the National Key Research and Development Program of China (2017YFA0604902).

Conflicts of Interest: The authors declare no conflict of interest.

\section{References}

1. Zhao, L.; Deng, J.; Sun, P.; Liu, J.; Ji, Y.; Nakada, N.; Qiao, Z.; Tanaka, H.; Yang, Y. Nanomaterials for treating emerging contaminants in water by adsorption and photocatalysis: Systematic review and bibliometric analysis. Sci. Total Environ. 2018, 627, 1253-1263. [CrossRef] [PubMed]

2. Jassby, D.; Cath, T.Y.; Buisson, H. The role of nanotechnology in industrial water treatment. Nat. Nanotechnol. 2018, 13, 670-672. [CrossRef] [PubMed]

3. Li, S.; Shen, X.; Liu, J.; Zhang, L. Synthesis of $\mathrm{Ta}_{3} \mathrm{~N}_{5} / \mathrm{Bi}_{2} \mathrm{MoO}_{6}$ core-shell fiber-shaped heterojunctions as efficient and easily recyclable photocatalysts. Environ. Sci. Nano 2017, 4, 1155-1167. [CrossRef]

4. Liu, Z.; Leow, W.R.; Chen, X. Bio-inspired plasmonic photocatalysts. Small Methods 2019, 3, 1800295. [CrossRef]

5. Cates, E.L. Photocatalytic water treatment: So where are we going with this? Environ. Sci. Technol. 2017, 51, 757-758. [CrossRef]

6. Li, X.; Xiong, J.; Gao, X.; Huang, J.; Feng, Z.; Chen, Z.; Zhu, Y. Recent advances in $3 \mathrm{D}$ g- $\mathrm{C}_{3} \mathrm{~N}_{4}$ composite photocatalysts for photocatalytic water splitting, degradation of pollutants and $\mathrm{CO}_{2}$ reduction. J. Alloys Compd. 2019, 802, 196-209. [CrossRef]

7. Helal, A.; Harraza, F.A.; Ismail, A.A.; Sami, T.M.; Ibrahim, I.A. Hydrothermal synthesis of novel heterostructured $\mathrm{Fe}_{2} \mathrm{O}_{3} / \mathrm{Bi}_{2} \mathrm{~S}_{3}$ nanorods with enhanced photocatalytic activity under visible light. Appl. Catal. B Environ. 2017, 213, 18-27. [CrossRef]

8. Kong, L.; Ambrosi, A.; Zafir, M.; Guan, J.; Pumera, M. Smart robots: Self-propelled 3D-printed Aircraft Carrier of light-powered smart micromachines for large-volume nitroaromatic explosives removal. Adv. Funct. Mater. 2019, 29, 190387.

9. Yang, L.L.; Han, Q.F.; Wang, X.; Zhu, J.W. Highly efficient removal of aqueous chromate and organic dyes by ultralong HCOOBiO nanowires. Chem. Eng. J. 2015, 262, 169-178. [CrossRef]

10. Xiong, J.Y.; Cheng, G.; Lu, Z.; Tang, J.L.; Yu, X.L.; Chen, R. BiOCOOH hierarchical nanostructures: Shape-controlled solvothermal synthesis and photocatalytic degradation performances. Cryst. Eng. Comm. 2011, 13, 2381-2390. [CrossRef]

11. Cui, Y.; Zhang, X.; Zhang, H.; Cheng, Q.; Cheng, X. Construction of BiOCOOH/g- $\mathrm{C}_{3} \mathrm{~N}_{4}$ composite photocatalyst and its enhanced visible light photocatalytic degradation of amido black 10B. Sep. Purif. Technol. 2019, 210, 125-134. [CrossRef]

12. Chen, P.; Zhang, Q.; Su, Y.; Shen, L.; Wang, F.; Liu, H.; Liu, Y.; Cai, Z.; Lv, W.; Liu, G. Accelerated photocatalytic degradation of diclofenac by a novel CQDs/BiOCOOH hybrid material under visible-light irradiation: Dechloridation, detoxicity, and a new superoxide radical model study. Chem. Eng. J. 2018, 332, 737-748. [CrossRef]

13. Li, S.; Mo, L.; Liu, Y.; Zhang, H.; Ge, Y.; Zhou, Y. $\mathrm{Ag}_{2} \mathrm{CO}_{3}$ decorating BiOCOOH microspheres with enhanced full-spectrum photocatalytic activity for the degradation of toxic pollutants. Nanomaterials 2018, 8, 914. [CrossRef] [PubMed]

14. Li, S.; Chen, J.; Liu, Y.; Xu, K.; Liu, J. In situ anion exchange strategy to construct flower-like BiOCl/BiOCOOH p-n heterojunctions for efficiently photocatalytic removal of aqueous toxic pollutants under solar irradiation. J. Alloys Compd. 2019, 781, 582-588. [CrossRef] 
15. Li, S.; Chen, J.; Jiang, W.; Liu, Y.; Ge, Y.; Liu, J. Facile construction of flower-like bismuth oxybromide/bismuth oxide formate $\mathrm{p}-\mathrm{n}$ heterojunctions with significantly enhanced photocatalytic performance under visible light. J. Colloid Interface Sci. 2019, 548, 12-19. [CrossRef]

16. Xu, B.Y.; An, Y.; Liu, Y.Y.; Huang, B.B.; Qin, X.Y.; Zhang, X.Y.; Dai, Y.; Whangbo, M.-H. An efficient visible-light photocatalyst made from a nonpolar layered semiconductor by grafting electron-withdrawing organic molecules to its surface. Chem. Commun. 2016, 52, 13507-13510. [CrossRef]

17. Xu, J.; Wang, Y.; Niu, J.; Chen, M.; Teng, F. Preparation of $\mathrm{Bi}_{2} \mathrm{MoO}_{6}-\mathrm{BiOCOOH}$ plate-on-plate heterojunction photocatalysts with significantly improved photocatalytic performance under visible light irradiation. J. Taiwan Inst. Chem. Eng. 2019, 97, 326-335. [CrossRef]

18. Ye, R.; Zhao, J.; Wickemeyer, B.B.; Toste, F.D.; Somorjai, G.A. Foundations and strategies of the construction of hybrid catalysts for optimized performances. Nature Catal. 2018, 1, 318-325. [CrossRef]

19. Yao, X.; Liu, X. One-pot synthesis of ternary $\mathrm{Ag}_{2} \mathrm{CO}_{3} / \mathrm{Ag} / \mathrm{AgCl}$ photocatalyst in natural geothermal water with enhanced photocatalytic activity under visible light irradiation. J. Hazard. Mater. 2014, 280, 260-268. [CrossRef]

20. Hou, J.; Wang, Z.; Yang, C.; Zhou, W.; Jiao, S.; Zhu, H. Hierarchically plasmonic Z-scheme photocatalyst of $\mathrm{Ag} / \mathrm{AgCl}$ nanocrystals decorated mesoporous single-crystalline metastable $\mathrm{Bi}_{20} \mathrm{TiO}_{32}$ nanosheets. J. Phys. Chem. C 2013, 117, 5132-5141. [CrossRef]

21. Yang, S.-F.; Niu, C.-G.; Huang, D.-W.; Zhang, H.; Liang, C.; Zeng, G.-M. SrTiO 3 nanocubes decorated with $\mathrm{Ag} / \mathrm{AgCl}$ nanoparticles as photocatalysts with enhanced visible-light photocatalytic activity towards the degradation of dyes, phenol and bisphenol A. Environ. Sci. Nano 2017, 4, 585. [CrossRef]

22. Liang, X.; Wang, P.; Li, M.; Zhang, Q.; Wang, Z.; Dai, Y.; Zhang, X.; Liu, Y.; Whangbo, M.-H.; Huang, B. Adsorption of gaseous ethylene via induced polarization on plasmonic photocatalyst $\mathrm{Ag} / \mathrm{AgCl} / \mathrm{TiO} \mathrm{O}_{2}$ and subsequent photodegradation. Appl. Catal. B 2018, 220, 356-361. [CrossRef]

23. Cui, W.; Li, X.; Gao, C.; Dong, F.; Chen, X. Ternary Ag/AgCl-(BiO) ${ }_{2} \mathrm{CO}_{3}$ composites as high-performance visible-light plasmonic photocatalysts. Catal. Today 2017, 284, 67-76. [CrossRef]

24. Jiang, Z.; Pan, J.; Wang, B.; Li, C. Two dimensional Z-scheme $\mathrm{AgCl} / \mathrm{Ag} / \mathrm{CaTiO}{ }_{3}$ nano-heterojunctions for photocatalytic hydrogen production enhancement. Appl. Surf. Sci. 2018, 436, 519-526. [CrossRef]

25. Ao, Y.; Bao, J.; Wang, P.; Wang, C. A novel heterostructured plasmonic photocatalyst with high photocatalytic activity: Ag@AgCl nanoparticles modified titanium phosphate nanoplates. J. Alloys Compd. 2017, 698, 410-419. [CrossRef]

26. Li, S.; Hu, S.; Jiang, W.; Liu, Y.; Zhou, Y.; Liu, Y.; Mo, L. Hierarchical architectures of bismuth molybdate nanosheets onto nickel titanate nanofibers: Facile synthesis and efficient photocatalytic removal of tetracycline hydrochloride. J. Colloid Interface Sci. 2018, 521, 42-49. [CrossRef]

27. Li, S.; Hu, S.; Jiang, W.; Liu, Y.; Liu, J.; Wang, Z. Facile synthesis of flower-like $\mathrm{Ag}_{3} \mathrm{VO}_{4} / \mathrm{Bi}_{2} \mathrm{WO}_{6}$ heterojunction with enhanced visible-light photocatalytic activity. J. Colloid Interface Sci. 2017, 501, 156-163. [CrossRef]

28. Akbarzadeh, R.; Fung, C.S.L.; Rather, R.A.; Lo, I.M.C. One-pot hydrothermal synthesis of g- $\mathrm{C}_{3} \mathrm{~N}_{4} / \mathrm{Ag} / \mathrm{AgCl} / \mathrm{BiVO} 4$ micro-flower composite for the visible light degradation of ibuprofen. Chem. Eng. J. 2018, 341, 248-261. [CrossRef]

29. Li, S.; Hu, S.; Jiang, W.; Zhou, Y.; Liu, J.; Wang, Z. Facile synthesis of cerium oxide nanoparticles decorated flower-like bismuth molybdate for enhanced photocatalytic activity toward organic pollutant degradation. J. Colloid Interface Sci. 2018, 530, 171-178. [CrossRef]

30. Zheng, J.; Chang, F.; Jiao, M.; Xu, Q.; Deng, B.; Hu, X. A visible-light-driven heterojuncted composite $\mathrm{WO}_{3} / \mathrm{Bi}_{12} \mathrm{O}_{17} \mathrm{Cl}_{2}$ : Synthesis, characterization, and improved photocatalytic performance. J. Colloid Interface Sci. 2018, 510, 20-31. [CrossRef]

31. Regulska, E.; Breczko, J.; Basa, A. Pristine and graphene-quantum-dots-decorated spinel nickel aluminate for water remediation from dyes and toxic pollutants. Water 2019, 11, 953. [CrossRef]

32. Li, X.; Xiong, J.; Xu, Y.; Feng, Z.; Huang, J. Defect-assisted surface modification enhances the visible light photocatalytic performance of $\mathrm{g}-\mathrm{C}_{3} \mathrm{~N}_{4} @ \mathrm{C}-\mathrm{TiO}_{2}$ direct Z-scheme heterojunction. Chin. J. Catal. 2019, 40, 424-443. [CrossRef]

33. Wen, X.-J.; Niu, C.-G.; Huang, D.-W.; Zhang, L.; Liang, C.; Zeng, G.-M. Study of the photocatalytic degradation pathway of norfloxacin and mineralization activity using a novel ternary $\mathrm{Ag} / \mathrm{AgCl}-\mathrm{CeO}_{2}$ photocatalyst. J. Catal. 2017, 355, 73-86. [CrossRef] 
34. Li, S.; Hu, S.; Jiang, W.; Zhang, J.; Xu, K.; Wang, Z. In situ construction of $\mathrm{WO}_{3}$ nanoparticles decorated $\mathrm{Bi}_{2} \mathrm{MoO}_{6}$ microspheres for boosting photocatalytic degradation of refractory pollutants. J. Colloid Interface Sci. 2019, 556, 335-344. [CrossRef] [PubMed]

35. Chang, F.; Wu, F.; Zheng, J.; Cheng, W.; Yan, W.; Deng, B.; Hu, X. In-situ establishment of binary composites a- $\mathrm{Fe}_{2} \mathrm{O}_{3} / \mathrm{Bi}_{12} \mathrm{O}_{17} \mathrm{Cl}_{2}$ with both photocatalytic and photo-Fenton features. Chemosphere 2018, 210, 257-266. [CrossRef] [PubMed]

36. Chai, B.; Wang, X. Enhanced visible light photocatalytic activity of BiOI/BiOCOOH composites synthesized via ion exchange strategy. RSC Adv. 2015, 5, 7589-7596. [CrossRef]

37. Zhang, J.; Niu, C.; Ke, J.; Zhou, L.; Zeng, G. Ag/AgCl/Bi2MoO6 composite nanosheets: A plasmonic Z-scheme visible light photocatalyst. Catal. Commun. 2015, 59, 30-34. [CrossRef]

38. Li, X.; Fang, S.; Ge, L.; Han, C.; Qiu, P.; Liu, W. Synthesis of flower-like Ag/AgCl-Bi $2 \mathrm{MoO}_{6}$ plasmonic photocatalysts with enhanced visible-light photocatalytic performance. Appl. Catal. B 2015, 176-177, 62-69. [CrossRef]

39. Asadzadeh-Khaneghah, S.; Habibi-Yangjeh, A.; Abedi, M. Decoration of carbon dots and AgCl over g- $\mathrm{C}_{3} \mathrm{~N}_{4}$ nanosheets: Novel photocatalysts with substantially improved activity under visible light. Sep. Purif. Technol. 2018, 199, 64-77. [CrossRef]

(C) 2019 by the authors. Licensee MDPI, Basel, Switzerland. This article is an open access article distributed under the terms and conditions of the Creative Commons Attribution (CC BY) license (http://creativecommons.org/licenses/by/4.0/). 